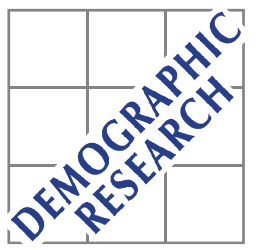

Demographic Research a free, expedited, online journal of peer-reviewed research and commentary in the population sciences published by the Max Planck Institute for Demographic Research Konrad-Zuse Str. 1, D-18057 Rostock · GERMANY www.demographic-research.org

DEMOGRAPHIC RESEARCH

VOLUME 23, ARTICLE 13, PAGES 365-398

PUBLISHED 13 AUGUST 2010

http://www.demographic-research.org/Volumes/Vol23/13/

DOI: $10.4054 /$ DemRes.2010.23.13

Research Article

\title{
Age, relationship status, and the planning status of births
}

\section{Sarah R. Hayford}

Karen Benjamin Guzzo

(C) 2010 Sarah R. Hayford and Karen Benjamin Guzzo.

This open-access work is published under the terms of the Creative Commons Attribution NonCommercial License 2.0 Germany, which permits use, reproduction \& distribution in any medium for non-commercial purposes, provided the original author(s) and source are given credit.

See http:// creativecommons.org/licenses/by-nc/2.0/del 


\section{Table of Contents}

1 Introduction $\quad 366$

$2 \quad$ Age, partnership, and planned births 367

$2.1 \quad$ Planning status and age 368

$\begin{array}{lll}2.2 & \text { Planning status and partnership } & 369\end{array}$

2.3 Hypotheses 370

$3 \quad$ Measurement and analytic approach $\quad 370$

$\begin{array}{lll}3.1 & 370\end{array}$

$\begin{array}{lll}3.2 & 372\end{array}$

$4 \quad$ Data and methods $\quad 317$

4.1 Data 373

$\begin{array}{lll}4.1 & \text { Conclusion and future directions } & 373\end{array}$

$\begin{array}{lll}4.2 & \text { Dependent variable } & 374\end{array}$

$\begin{array}{lll}4.3 & \text { Independent variables } & 375\end{array}$

$5 \quad$ Results $\quad 377$

$\begin{array}{lll}5.1 & \text { Descriptive results } & 377\end{array}$

$\begin{array}{lll}5.2 & \text { Multivariate results } & 379\end{array}$

$\begin{array}{lll}6 & \text { Discussion } & 387\end{array}$

$\begin{array}{lll}6.1 & \text { Limitations } & 388\end{array}$

$\begin{array}{lll}6.2 & \text { Conclusion } & 389\end{array}$

$\begin{array}{ll}\text { References } & 390\end{array}$

Appendix: Impact of imputed relationship status data on results $\quad 396$ 


\title{
Age, relationship status, and the planning status of births
}

\author{
Sarah R. Hayford ${ }^{1}$ \\ Karen Benjamin Guzzo ${ }^{2}$
}

\begin{abstract}
In the United States historically, births to older mothers have been more likely to be planned than births to younger mothers, and births to unmarried women have been less likely to be planned than births to married women. As the average age of mothers has increased and more births have occurred outside of marriage in the United States, the intersection of these trends may have weakened the traditional linkage between age and birth planning status. In this article, we examine differences by maternal age in the planning status of births using the 2002 National Survey of Family Growth. We find that age is strongly associated with planning status, but the association is reduced in magnitude when controlling for relationship status and is stronger for first and second births than for higher-parity births. Further, the association between union status and the planning status of births varies by race-ethnicity.
\end{abstract}

${ }^{1}$ Arizona State University. E-mail: Sarah.Hayford@asu.edu.

${ }^{2}$ Kutztown University. E-mail: guzzo@kutztown.edu. 


\section{Introduction}

Unplanned fertility ${ }^{3}$ in the United States is high relative to other developed countries, with more than a third of births between 1997 and 2002 characterized as unplanned (Chandra et al. 2005; Morgan 2003). Births that are not actively planned represent a woman's lack of control over her reproductive life and can affect other aspects of women's lives as well, such as employment and educational attainment. In addition, such births are associated with negative health consequences for both mothers and children (e.g., Crissey 2005; Hummer, Hack, and Raley 2004; Korenman, Kaestner, and Joyce 2001; Weller, Eberstein, and Bailey 1987). With such negative potential outcomes associated with unplanned fertility, the U.S. Department of Health and Human Services set the goal of reducing unplanned pregnancies from $50 \%$ to $30 \%$ of all U.S. pregnancies (U.S. Department of Health and Human Services 2000).

In order to reduce unplanned fertility, it is vital to understand the context in which unplanned births occur. Although there is a large literature examining those who have unplanned births (e.g., Henshaw 1998; Musick 2002, 2007; Finer and Henshaw 2006), much of this research fails to consider how unplanned fertility varies across the social contexts of age, union status, parity, and race-ethnicity. Instead, these characteristics are often studied by themselves or only subgroups are studied. For instance, Musick's $(2002,2007)$ work focuses on fertility in nonmarital and cohabiting unions, excluding unplanned fertility occurring within a marriage, while Henshaw and Finer's (Henshaw 1998; Finer and Henshaw 2006) work is largely descriptive with little multivariate analysis. There remains a need to understand the complexity and variability of unplanned fertility across the life course and across socio-demographic characteristics.

Studying unplanned births can also shed light on social norms surrounding childbearing and the family life course (Musick 2002), which is especially salient in light of the dramatic demographic changes occurring among mothers in the United States. Since 1970, the average age at childbearing has increased, but this increase has been unevenly distributed across the population. Simultaneously, a growing proportion of births now take place outside of marriage (McLanahan 2004; Martin 2004). It is not clear whether social norms regarding the timing of childbearing, the relationship context of childbearing, and their intersection have changed to accompany these behavioral shifts. In this analysis, we use data from the 2002 National Survey of Family Growth to assess socio-demographic variation in the likelihood that recent births in the

\footnotetext{
${ }^{3}$ Research literature has not reached a consensus on the definition and measurement of unplanned fertility. In United States academic literature and government reports, the term "unintended fertility" is used, and unintended births are defined in relation to women's desires at the time of conception. We use "unplanned" and "planning status" as general terms in this article. Our definition of unplanned is described in detail in the measurement and data sections.
} 
United States were planned. We focus on age and relationship context as the primary independent variables because past research shows these variables to be the central stratifying factors in the planning status of births (e.g., Chandra et al. 2005; Finer and Henshaw 2006), and because age and partnership are key factors in determining the normative context for childbearing. In addition, we consider the role of parity, distinguishing between first, second, and higher-order births. Finally, we pay particular attention to race-ethnicity, given the substantial diversity in childbearing behavior and planning status across U.S racial and ethnic groups.

\section{Age, partnership, and planned births}

Despite the public health interest in reducing the proportion of unplanned births, the factors leading to unplanned births in the United States are not well understood. Births to women in their late twenties and thirties are more likely to be planned than births to teenagers and women in their early twenties (Henshaw 1998; Finer and Henshaw 2006). In addition, unplanned birth rates are lower for partnered women - especially married women - than for women not in co-residential relationships (Chandra et al. 2005; Finer and Henshaw 2006). However, the relationship between age and partnership in producing unplanned births and the degree to which these factors are related to socioeconomic disadvantage have not been determined. The need to understand the association between age, partnership, and unplanned fertility is increasingly important as the demographic characteristics of births and mothers continue to change.

Over the past few decades, the profile of American mothers has changed extensively, particularly in regards to age and marital status. Between 1970 and 2006, the average age of first-time mothers increased 3.6 years, from 21.4 years to 25.0 years (Mathews and Hamilton 2009), with the average age at birth for all parities at 27.4 in 2006 (Martin et al. 2009) and fewer births occurring to very young women. These patterns suggest that recent births would be relatively likely to be planned given the traditional association between age and planning status. However, the proportion of births that were unplanned appears to have stagnated in the 1990s (Finer and Henshaw 2006). This plateau may be related to another, perhaps more dramatic, change among mothers: they are increasingly likely to be unmarried at birth. In $2007,39.7 \%$ of all births occurred outside of marriage, up from $18.4 \%$ in 1980 and only $5.3 \%$ in 1960 (Ventura and Bachrach 2000, Ventura 2009). About half of nonmarital births, though, occur to cohabiting women (Mincieli et al. 2007), and cohabiting women are more likely to report their births as planned than non-cohabiting unmarried women (Musick 2002). Although the timing and relationship context of childbearing behavior has changed, there is some evidence that norms regarding appropriate situations for 
childbearing have lagged behind changes in behavior. For instance, the majority of Americans continue to report that marriage is the ideal setting for having children (Thornton and Young-DeMarco 2001). The changing demographic profile of American mothers raises the question as to whether the traditional age- and partnershipdependence of birth planning remains.

\subsection{Planning status and age}

The reasons for age differences in planning status are not well understood. One explanation may be behavioral or experiential. Women may become better at preventing unplanned pregnancies as they age, either because of improved knowledge or cognitive abilities that allow them to use contraception more effectively, because of better bargaining power to limit unprotected sexual activity, or because of better motivation to avoid a(nother) child if the opportunity costs of children increase with age. Age differences in unplanned fertility may also be explained by social norms about the timing of childbearing; if some ages (i.e., teenage and young adult years) are seen as undesirable for childbearing, fewer women will plan children at those ages and proportionally more births at those ages will be unplanned. The rising age at first birth suggests that norms regarding the ideal ages of fertility may have shifted.

Associations between age at birth and planning status are likely to be parityspecific: women who have a first birth in their late twenties or later are, by definition, women who have not had children earlier. Avoiding childbearing in the teens and early twenties is possible evidence for the presence of motivation and ability to control fertility; thus, first births to women in their late twenties or older are less likely than first births to younger women to result from contraceptive failure or non-use of contraception. The relationship between age and planning status may be weaker for births after the first, since age at birth is no longer a signal for ability to manage childbearing.

In addition to direct norms about the appropriate ages for having children, indirect norms about the timing of fertility act through expectations for the sequencing of childbearing and other life events such as school leaving, employment, and especially marriage. To the extent that norms regarding birth timing are linked to marriage and relationship formation, the association between age and planning status should be reduced or disappear when controlling for the relationship context of births. 


\subsection{Planning status and partnership}

In the United States, despite increasing acceptance of nonmaritalchildbearing, marriage is still seen as the ideal locus for childbearing and childrearing, and married couples remain more likely to want children than unmarried people (Schoen et al. 1997; Thornton and Young-DeMarco 2001). Moreover, since marriage is a monogamous relationship in which regular sexual activity occurs, married couples generally use more reliable forms of contraception (Martinez et al. 2006), such that having a child often requires the decision not to employ contraceptive methods. Married women therefore report the lowest levels of unplanned fertility; in the late 1990s, more than threequarters of births to married women were planned (Chandra et al. 2005).

Some early research conflated unplanned and nonmarital fertility, assuming that all unplanned births took place outside of marriage and that all nonmarital births were unplanned (Musick 2002). However, a substantial proportion of births to unmarried women in the late 1990s were planned: $35 \%$ of births to women not living with a partner and almost half of births to cohabiting women (Chandra et al. 2005). The planning status of births outside marriage varies according to the socio-demographic characteristics of mothers, especially the characteristics of their partnerships. As cohabitation has become more prevalent in the United States, it is not clear to what extent cohabitation has become a normative setting for childbearing. On average, cohabiting unions in the United States are shorter and less stable than those in other developed countries (Heuveline and Timberlake 2004). The proportion of births in cohabiting unions has increased, but this increase is largely attributable to the number of women cohabiting and not to an increase in cohabiting birth rates (Raley 2001). Still, births to cohabiting women are substantially more likely to be planned than births outside of co-residential relationships (Chandra et al. 2005, Musick 2002).

The association between cohabitation and childbearing overall, and planned childbearing in particular, appears to be especially strong for Hispanic women, for whom cohabitation accounts for half of all nonmarital births, and to a lesser extent for non-Hispanic white women, for whom cohabitation accounts for $40 \%$ of all nonmarital births (Musick 2002; Martinez et al. 2006). While cohabitation increases the likelihood of a planned birth for blacks as well, only about $30 \%$ of black nonmarital births, and $20 \%$ of black births overall, occur within a cohabiting union (Musick 2002; Martinez et al 2006). Generally, previous research suggests that the role of cohabitation in the family system varies by race-ethnicity in the United States, with cohabiting unions being more stable, and more common situations for childbearing, for Hispanic women than for non-Hispanic white or black women (Landale and Fennelly 1992; Manning and Landale 1996; Oropesa 1996; Manning 2001). Black women are less likely to cohabit or marry than either Hispanic or non-Hispanic white women, but they are more likely to 
experience unplanned fertility (Martinez et al. 2006). These differences suggest that associations between union status and unplanned fertility may vary by race-ethnicity.

\subsection{Hypotheses}

Hypothesis 1: Age at birth is positively associated with the likelihood that a birth will be planned.

Hypothesis 1a: Controlling for relationship status and socio-demographic characteristics at birth may reduce or eliminate the magnitude of the association.

Hypothesis $1 \mathrm{~b}$ : The association between age and planning status is stronger for first births than higher-order births.

Hypothesis 2: Births to married women are more likely to be planned than births to unmarried women, and births to cohabiting women are more likely to be planned than births to women not in a co-residential relationship.

Hypothesis 2a: The association between relationship status and planning status is weaker among minority women, especially black women, than among non-Hispanic white women.

\section{Measurement and analytic approach}

\subsection{Measurement}

The associations between age at birth and other behaviors of interest are strongly nonlinear. There is no consensus as to the best way of categorizing age, but there is agreement that there are important differences in the causes and consequences of childbearing at different ages in the United States (e.g., Edwards 2002; KoropeckyjCox, Pienta, and Brown 2007; Martin 2004; Mirowsky and Ross 2002; Morgan 1996; Morgan and Rindfuss 1999; Rindfusss, Morgan, and Offutt 1996; Rindfuss, Morgan, and Swicegood 1988; Sullivan 2005; Wu and MacNeil 2002). In this analysis, we divide age at birth into five categories: below age 18, age 18-19, age 20-24, age 25-29, and age 30 and over. We base our choice of categories on exploratory analysis as well as previous literature studying age patterns of fertility in the United States. In particular, the separation of births to women under age 18 (the standard age of secondary school 
completion in the United States) and women age 18 and 19 is a standard distinction used in describing and tabulating fertility in both government reports and academic literature in the United States (see, e.g., Chandra et al. 2005 for NSFG reports; Ventura 2009 for vital statistics reports; Finer and Henshaw 2006 for research specifically on unplanned fertility) and internationally, particularly when discussing teenage fertility (see, e.g., UNICEF 2001). For convenience, we occasionally refer to women having children in their late twenties and over as "older" women or "older" mothers. Clearly, these women are not "old" in terms of their position in the life span, but, in the context of contemporary fertility in the United States, they can be considered "older" mothers compared to early childbearers.

Measuring fertility plans poses both empirical and conceptual difficulties. Longitudinal studies have shown widespread differences between women's stated plans about whether to have children and their subsequent reports of whether children were wanted (Joyce, Kaestner, and Korenman 2002; Westoff and Ryder 1977; Williams and Abma 2000). These differences are partly attributable to women's unwillingness to describe an existing child as unwanted and to the inherent complexities of feelings about pregnancy, childbearing, and contraception (Thomson and Brandreth 1995; Trussell, Vaughan, and Stanford 1999; Zabin 1999). Women may have strong desires to have a child at some future point but may not want a child with a particular partner or at a particular time. Ambivalence about the use of contraception and reluctance to completely plan motherhood further complicate the process of determining the wantedness of pregnancies (Zabin 1999). Continued normative pressure against nonmarital childbearing may also muddy the question of whether nonmarital births are wanted. Similarly, disapproval of childbearing at young ages in some social groups may make young women more likely to report births as unwanted.

In an attempt to minimize this confusion, we focus on women's reports of whether a pregnancy was planned rather than her assessment of whether a birth was wanted. Planning status is largely determined based on behavior. Pregnancies that occur while a woman is practicing contraception - that is, pregnancies resulting from contraceptive failure - are labeled as unplanned. Conceptions that take place while women are not actively preventing pregnancy are more difficult to classify. For sexually active women, taking action is required to prevent conception, while taking no action usually results (eventually) in pregnancy. Thus, becoming pregnant does not require an active desire to conceive, though certainly some women feel an active desire to conceive and take concrete steps to carry out this desire (see, e.g., Miller 1986).

Recent research has addressed this problem by combining women's reports of contraceptive use with their reported desires and plans at the time of conception (e.g. Crissey 2005; Guzman, Manlove, and Moore 2006). In this analysis, we combine women's reports on contraceptive use and their reasons for discontinuation or non-use. 
Planned pregnancies are pregnancies that result from the deliberate choice not to use contraception in order to get pregnant. In our classification, planning includes both an objective behavioral component (not using contraception) and a subjective assessment of that behavior (in order to get pregnant). Pregnancies resulting from contraceptive failure are labeled as unplanned. In addition, we label pregnancies unplanned if a woman reports that she did not use contraception or that she stopped using contraception but that her non-use was not because she wanted to get pregnant. (More specific information on the variables used to measure planning status is presented in the data and methods section.)

\subsection{Analytic approach}

Births are the unit of analysis in this article, with planning status of birth the dependent variable. In essence, this article examines recent births in the United States and compares the contexts of planned and unplanned births. A birth is the outcome of a long series of events and decisions, including the decision to be sexually active, the decision to form a relationship, the decision whether or not to use contraception, the event of conception, and the decision to carry a pregnancy to term. It is estimated that about half of unplanned pregnancies in the United States are aborted (Boonstra et al. 2006). Unplanned pregnancies to unmarried women are more likely to end in abortion than those to married women, and the proportion of unplanned pregnancies aborted increases with age (Finer and Henshaw 2006). In addition, African American women are more likely to terminate an unplanned pregnancy than either Hispanic women or nonHispanic white women (ibid.) Thus, unplanned births are a non-random subset of unplanned pregnancies. This analysis therefore cannot speak to behavioral processes leading to pregnancies but only to the context of births.

From the perspective of an individual woman, each of the decisions leading to an unplanned birth could be modeled separately. However, these decisions are clearly not independent, and in the contemporary American family system, certain combinations of decisions tend to cluster together. Age at birth, socioeconomic status, and marital status at birth vary jointly, and this joint variation produces stratified patterns of family formation (Ellwood and Jencks 2004; McLanahan 2004; Sullivan 2005). These patterns can be thought of as social models of childbearing. Clearly, individual life courses vary from these stylized models. However, these empirical regularities provide a way of understanding the social meanings of fertility. Considering births as an outcome is one way of assessing the prevalence of these social models of fertility. 


\section{Data and methods}

\subsection{Data}

Analyses use the 2002 cycle of the National Survey of Family Growth (NSFG), which interviewed 7,643 women about their union and fertility history. Respondents were also surveyed about their use of contraception, education and employment status, and attitudes toward family and childbearing. The NSFG is nationally representative of women aged 15-44 at the time of the survey. However, the births reported in the NSFG are not nationally representative of births in the periods before the survey: because the survey collects retrospective data from a limited age range of women, observations before the survey are age-censored. (For a more detailed discussion of problems related to age censoring, see, e.g., Bumpass and Lu 2000; Kennedy and Bumpass 2008.) This censoring becomes more severe farther back in time. In the 1970s, for example, only births to women age 25 and younger are observed (since mothers older than 25 in the 1970s would have aged out of the NSFG sample frame by 2002). In order to approximate nationally representative period data, we limit our analysis to births from 1990 until the survey, roughly a twelve-year period. According to age distributions of births taken from vital statistics data, the births observed by the NSFG for the period after 1990 (births at age 33 and younger in 1990, 34 and younger in 1991, etc.) represent over $95 \%$ of births in the United States during this period (authors' calculations based on Centers for Disease Control n.d.).

As noted above, births are the unit of analysis, with planning status of birth the dependent variable and age and relationship status at conception the primary independent variables. Births with missing values on independent or dependent variables were excluded from analysis ( $\mathrm{n}=42$ births). Because of the large number of missing values for respondent's mother's education and mother's age at first birth, we code missing values for these variables as separate categories.

Due to an error in the administration of the survey, marriage end dates are missing for some previously married women. Dates are missing for all women who divorced men with children from previous relationships and for most currently separated respondents; in all, end dates are missing for more than a third of marriages that ended in divorce (Kennedy and Bumpass 2008). Because marriages with missing end dates are not randomly distributed, dropping births affected by missing dates may bias results, but it is not clear what direction results would be biased in. Missing end dates were imputed by the NSFG staff, but it is possible that the marital status of births to these women is misattributed, so including the affected cases might also lead to incorrect results. We tested models both with and without these births $(n=389)$. Following Kennedy and Bumpass (2008), we also estimated models using two extreme 
assumptions: first, we assigned all births with imputed relationship status to the marital birth category, and second, we assigned all births with imputed relationship status to the previously married category. The only salient difference across the models was in the estimates of race-relationship status interactions. We present and discuss results from the models including the births with imputed dates as imputed by the NSFG staff; in the discussion of results, we note where results varied across samples. Results from all four analyses (without imputed cases; with imputed cases as imputed by NSFG staff; with imputed cases assigned to married; with imputed cases assigned to previously married) are included in an appendix. The final analytic sample contains 6,398 births to 3,646 women. Because the sample includes multiple births to some women, observations are not independent, and standard errors may be biased downward. To account for this problem, we use Huber-White sandwich estimators to produce corrected standard errors.

\subsection{Dependent variable}

The outcome of this analysis is whether a birth was planned. We construct the dependent variable based on women's reports of contraceptive use or non-use at the time of pregnancy. The NSFG collects detailed contraceptive histories from all women. Monthly method use histories are collected for the time period between January 1999 and the interview date. For pregnancies that occurred before January 1999, women were asked what (if any) contraception they used in the interval between their first sexual intercourse and the pregnancy (for the first pregnancy) or between the previous pregnancy and the reference pregnancy (for subsequent pregnancies), and whether they stopped using contraception before they became pregnant. Women who stopped using contraception or who had never used contraception were further asked if their non-use was because they themselves wanted to get pregnant at that time. Based on this series of questions, we divided births into pregnancies that were explicitly desired ("planned") and pregnancies that occurred when the woman was using contraception or pregnancies that were neither sought nor avoided ("unplanned"). Induced abortions tend to be underreported in survey data, even in countries with strong government support for abortion (Rossier 2003). In the United States, estimates based on comparisons with data from abortion providers suggest that less than half of abortions to women in the 2002 NSFG were reported (Jones and Kost 2007). Because survey data on abortion is not reliable, we analyze only live births, not all pregnancies. 


\subsection{Independent variables}

Our primary independent variable is age at birth. As discussed earlier, our specification of age is based on previous U.S. research and exploratory analyses, and we measure age at birth as a series of dummy variables: under age 18, age 18-19, age 20-24, age 25-29, and age 30 and over. We also focus on the association between relationship status at conception and planning status of births. We choose to model relationship status at conception rather than at birth because the context at the time of conception more closely approximates the decision-making context around the pregnancy. We divide relationship status at conception into five categories: never-married and non-cohabiting, never-married and cohabiting, married, previously married and non-cohabiting, and previously married and cohabiting. We distinguish between births to never-married and previously married women based on previous research that shows differential patterns of fertility between previously married and never married cohabitors (Loomis and Landale 1994). Analyzing relationship status at conception obscures the process of legitimation of cohabiting and unpartnered births. This exclusion may overstate the acceptability of births in certain types of relationships if, for instance, cohabiting women plan births and marriage at the same time such that planned conceptions in cohabiting unions result in marital births (Wu and Musick 2008). Exploratory models showed some differences in results when using relationship status at birth and when taking into account relationship transitions between conception and birth. However, associations between age and planning status were the same in all models, and model fit statistics were slightly better in models using relationship status at conception. We therefore focus on the association between relationship status at conception and planning status at birth.

Analyses control for parity and include age-parity interactions. We divide parity into three categories: first births, second births, and third and higher order births. Parity is included to capture the stratifying effects of first birth timing on childbearing behavior as well as the effects of surpassing the U.S.'s average desired family size of two children (Hagewen and Morgan 2005). We also include age-parity interactions to account for distinctions between the associations between age and planning status attributable to chronological effect of aging and those stemming from parity-specific norms regarding appropriate ages to start childbearing. Because there are relatively few higher-order births among young women, we collapse age-parity categories for some interactions.

We control for race and Hispanic origin of mothers and include interactions between race and relationship status. The umbrella term "Hispanic" includes both foreign-born and native-born women from a variety of national origins; fertility and family formation behavior vary substantially within these subgroups (Landale and 
Oropesa 2007). Sample sizes in the NSFG are not large enough to subdivide Hispanic women by both nativity and national origin, but we do distinguish between foreign-born and native-born Hispanic women. We include interactions between race and relationship status to account for race-ethnic differences in the acceptance of childbearing in cohabiting unions and outside of co-residential relationships. In exploratory analysis, interactions for native-born Hispanic women were neither individually not jointly statistically significant and did not improve model fit. We therefore include interactions for African-American and foreign born Hispanic women only.

We also include variables reflecting the socioeconomic status of the mother, both to assess whether the relationship between age and planning status is explained by compositional differences between older and younger mothers and to test the association of socioeconomic status and planning status. As measures of socioeconomic status, we use information about the respondent's childhood and family of origin as proxies for adult socioeconomic status. Standard measures of individual socioeconomic status such as education and income are problematic in this analysis, as they are closely related to age ${ }^{4}$ and may be endogenous to fertility before the survey, if women who have unplanned births achieve lower levels of education or income than women with planned fertility. Prior waves of the NSFG included a detailed education history, but the 2002 cycle only has information on the date a high school degree was received. We examine respondent's educational achievement at the time of survey in descriptive statistics and include an indicator of whether the woman had a high school degree at the time of conception in all models. For the most part, however, we rely on maternal education, maternal age at first birth, and childhood family structure, three measures of family of origin characteristics and childhood living situations which are strongly correlated with adult achievement but not so closely confounded with the dependent variable. We include controls for calendar year in all models in order to account for changes over time in attitudes toward nonmarital fertility. In exploratory analyses, we tested for interactions between calendar year and other key independent variables but did not find any statistically significant interactions in this twelve-year span.

\footnotetext{
${ }^{4}$ The age at on-time high school graduation in the United States is 18. Ages for on-time completion of college degrees are 20 (for two-year degrees) and 22 (for four-year degrees). However, U.S. post-secondary institutions provide relatively open access, and non-standard progression through university - delayed entrance, exit and reentrance, delayed completion - is common. For example, only half of bachelor's degree recipients in 1999-2000 completed their degree by age 22, with 35\% being 23-29 years old, 9\% 30-39 years old, and $7 \%$ aged 40 or older (Bradburn et al. 2003).
} 


\section{Results}

\subsection{Descriptive results}

Table 1 describes variation in the planning status of births by socioeconomic and demographic characteristics of the mother and by relationship status at conception, as well as the distribution of births by these characteristics in our sample.

Table 1: Proportion of births planned according to characteristics of the mother

\begin{tabular}{|c|c|c|c|}
\hline & Percent of births planned & Number of births & Percent of sample \\
\hline All births & 49 & 6398 & \\
\hline \multicolumn{4}{|l|}{ Age at birth } \\
\hline Under 18 & 18 & 378 & 5 \\
\hline $18-19$ & 26 & 607 & 8 \\
\hline $20-24$ & 38 & 1886 & 26 \\
\hline $25-29$ & 54 & 1798 & 29 \\
\hline 30 and over & 63 & 1729 & 32 \\
\hline \multicolumn{4}{|l|}{ Relationship status at conception } \\
\hline Never-married, not cohabiting & 14 & 1242 & 16 \\
\hline Never-married, cohabiting & 31 & 1438 & 19 \\
\hline Previously married, not cohabiting & 14 & 119 & 2 \\
\hline Previously married, cohabiting & 46 & 321 & 5 \\
\hline Married & 65 & 3278 & 58 \\
\hline \multicolumn{4}{|l|}{ Parity } \\
\hline First birth & 50 & 2814 & 42 \\
\hline Second birth & 54 & 2123 & 33 \\
\hline Third or higher order birth & 41 & 1461 & 24 \\
\hline \multicolumn{4}{|l|}{ Race } \\
\hline Non-Hispanic white & 53 & 3371 & 68 \\
\hline Non-Hispanic black & 27 & 1416 & 15 \\
\hline Native-born Hispanic & 43 & 815 & 8 \\
\hline Foreign-born Hispanic & 55 & 796 & 9 \\
\hline \multicolumn{4}{|l|}{ Family status at age 14} \\
\hline Not living with both biological parents & 40 & 2139 & 31 \\
\hline Living with both biological parents & 53 & 4259 & 69 \\
\hline \multicolumn{4}{|l|}{ Respondent's mother's education } \\
\hline Less than HS & 45 & 2118 & 28 \\
\hline HS/GED & 51 & 2160 & 37 \\
\hline Some college/AA degree & 50 & 1163 & 19 \\
\hline $\mathrm{BA}$ or higher & 54 & 795 & 13 \\
\hline Missing & 32 & 162 & 2 \\
\hline
\end{tabular}


Table 1: (Continued)

\begin{tabular}{lccc}
\hline & Percent of births planned & Number of births & Percent of sample \\
\cline { 2 - 4 } Respondent's mother's age at first birth & 38 & 1511 & 20 \\
Under 18 & 49 & 1457 & 22 \\
$18-19$ & 51 & 2371 & 41 \\
$20-24$ & 56 & 661 & 10 \\
$25-29$ & 60 & 252 & 4 \\
30 and over & 48 & 146 & 3 \\
Missing & & & 32 \\
Education at time of conception & 34 & 2381 & 68 \\
No high school degree & 56 & 4017 & 18 \\
High school degree & & & 34 \\
Education at time of survey & 39 & 1331 & 27 \\
Less than HS & 41 & 2162 & 21 \\
HS/GED & 48 & 1732 & 1173 \\
Some college/AA degree & 70 & & \\
BA or higher & & & \\
\hline
\end{tabular}

Data: National Survey of Family Growth, 2002; births in the United States after 1990. Births with missing values on dependent or independent variables excluded.

Percents calculated using sample weights. See text for details of variables and sample. $p \leq .05 ;{ }^{* *} p \leq .01 ;{ }^{* * *} p \leq .001$

Overall, just under half of births in the sample were planned, with second births slightly more likely and third and higher order births slightly less likely to be planned than first births. Consistent with previous research, in this sample the proportion of births that were planned increased steadily with the age of the mother, with $63 \%$ of births to women over age 30 planned compared to only $18 \%$ of births to women under age 18. Planning status also varied by whether the mother was in a co-residential relationship at conception; births to women who were not in a co-residential relationship at conception were the least likely to be planned (14\% of births to nevermarried women and to previously married women). Births conceived by cohabiting women were more likely to be planned (31\% and $46 \%$ for never married and previously married cohabiters, respectively) than births to single women but less likely than births conceived by married women (65\%). Non-Hispanic white women were more likely to report births as planned than either African American or native-born Hispanic women. Foreign-born Hispanic women report the highest proportion of births planned of any race-ethnic groups. Other socio-demographic characteristics are also associated with planning status as expected, with generally more unplanned births reported by disadvantaged mothers. 


\subsection{Multivariate results}

To disentangle the relationships between age, relationship status, parity, and sociodemographic characteristics, we turn to multivariate analyses predicting birth planning status. Table 2 shows results from three nested models: the first showing the unconditional relationship between age and planning status; the second controlling for relationship status; and the third controlling for a full set of socio-demographic characteristics.

Table 2: Logistic regression of planning status on age, relationship at conception, and other characteristics

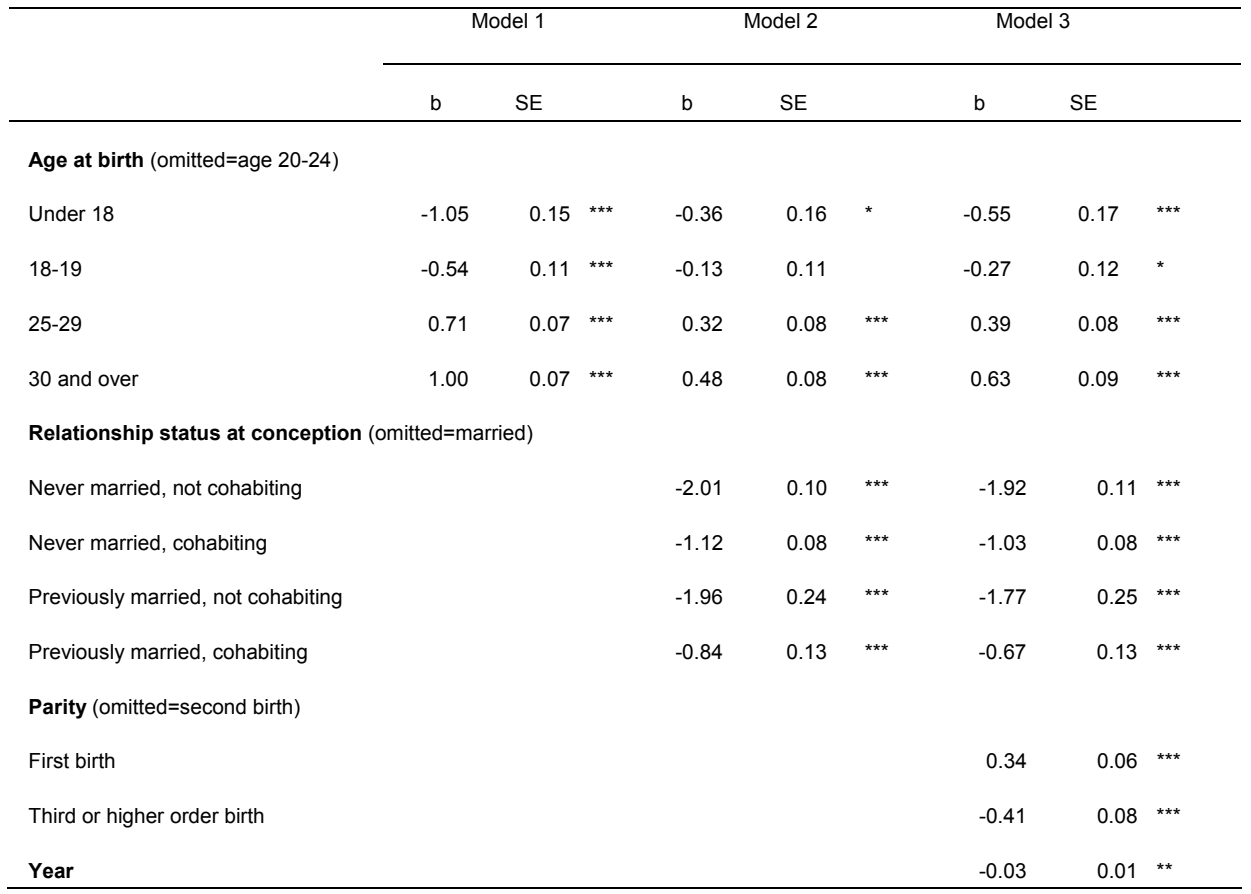


Hayford \& Guzzo: Age, relationship status, and the planning status of births

Table 2: (Continued)

\begin{tabular}{|c|c|c|c|c|c|c|c|}
\hline & \multicolumn{2}{|c|}{ Model 1} & \multicolumn{2}{|c|}{ Model 2} & \multicolumn{3}{|c|}{ Model 3} \\
\hline & b & SE & b & SE & b & SE & \\
\hline \multicolumn{8}{|l|}{ Race (omitted=non-Hispanic white) } \\
\hline Native-born Hispanic & & & & & 0.09 & 0.10 & \\
\hline Foreign-born Hispanic & & & & & 0.33 & 0.12 & ** \\
\hline Non-Hispanic black & & & & & -0.28 & 0.09 & ** \\
\hline \multicolumn{8}{|c|}{ Family status at age 14 (omitted=not living with both biological parents) } \\
\hline Living with both biological parents & & & & & 0.12 & 0.07 & \\
\hline \multicolumn{8}{|c|}{ Respondent's mother's education (omitted=high school degree/GED) } \\
\hline Missing & & & & & 0.13 & 0.23 & \\
\hline Less than $\mathrm{HS}$ & & & & & 0.03 & 0.09 & \\
\hline Any college & & & & & -0.08 & 0.08 & \\
\hline \multicolumn{8}{|c|}{ Respondent's mother's age at first birth (omitted=20-24) } \\
\hline Missing & & & & & 0.23 & 0.25 & \\
\hline Under 18 & & & & & -0.08 & 0.10 & \\
\hline $18-19$ & & & & & 0.07 & 0.08 & \\
\hline Age 25 and over & & & & & -0.04 & 0.10 & \\
\hline \multicolumn{8}{|c|}{ Education at time of conception (omitted=no high school degree) } \\
\hline High school degree & & & & & 0.09 & 0.08 & \\
\hline Intercept & -0.58 & $0.05 * * *$ & 0.26 & $0.07^{* * *}$ & 50.92 & 16.66 & ** \\
\hline Pseudo-log likelihood & & 11.6 & & 3813.9 & & -3726.5 & \\
\hline
\end{tabular}

Data: National Survey of Family Growth, 2002. N = 6398 births to 3646 women; standard errors corrected for clustering. See text for details of variables and sample. $p \leq .05 ;{ }^{* \star} p \leq .01 ;{ }^{* \star *} p \leq .001$

Model 1, in which age is the only independent variable, shows as expected that births to women at later ages are more likely to be planned. The proportion of births that are planned increases across the range of ages; the odds of a planned birth to a mother under age 18 are only about a third of the odds of a birth to a woman age 20-24 $\left(\mathrm{OR}=\mathrm{e}^{-1.05}=0.35\right)$, while the odds for births to women age 30 and over are almost 3 times greater $(\mathrm{OR}=2.72)$. These associations are substantially reduced (by more than 
half) when controlling for the mother's relationship status at the time of conception (Model 2). Model 2 also shows substantial variation in the planning status of births according to the relationship status of the mother at conception. Relative to mothers who were married at conception, births to unmarried mothers - both single and cohabiting - are less likely to be planned. These differences are largest for women not in a co-residential relationship at the time of conception. The odds of a birth conceived to a never-married cohabiting woman being planned are more than twice as great as the odds for a birth conceived to a never-married woman not in a co-residential relationship. For previously married women, the odds that a birth to a cohabiting woman is planned are almost three times higher than those of a birth to a single woman. Comparing the odds that a birth would be planned, the difference between marriage and cohabitation is smaller, and the difference between co-residential and non-co-residential relationships is larger, for previously married women than for never married women. As a setting for planned childbearing, cohabitation and marriage appear to function fairly similarly for previously married women.

Model 3 adds a full set of sociodemographic controls, including parity, raceethnicity, and socioeconomic background. Controlling for these characteristics increases the age coefficients relative to Model 2, although the coefficients are still half the size as in the unconditional model. The coefficients for the relationship status variables are only minimally attenuated when controlling for other characteristics. That is, the lower proportion of planned births in nonmarital relationships is not attributable to the characteristics of women who have children outside of marriage.

First births are more likely to be reported as planned than second births $(b=0.34)$, and third and higher order births are less likely to be reported as planned than second births $(b=-0.41)$. Births to African American women are less likely to be planned than births to non-Hispanic white women, even controlling for other characteristics, and births to foreign-born Hispanic women are more likely to be planned. However, other sociodemographic characteristics are not significantly associated with the planning status of births when accounting for other covariates. These socioeconomic characteristics are strongly associated with the process of selection into marriage and cohabiting unions and with the timing of fertility. The bivariate associations shown in Table 1 appear to be largely accounted for by controlling for age and relationship status at birth.

Table 3 shows two models allowing for interactions between age and parity (Model 4) and between age and parity and between race-ethnicity and relationship status at conception (Model 5). Predicted probabilities generated from these models are show in Figures 1 and 2. Because there are few high-parity births at young ages, ageparity interactions combine births in the two youngest age categories and combine second and third births. Of course, age is related to parity at the individual level - 
mothers of higher parity births are of necessity older than when they had their first birth. However, given the large variation in first birth timing in the United States, the aggregate-level correlation between age and parity is low enough that age-parity cell sizes are large enough to support estimation.

Table 3: Logistic regression of planning status on age, relationship at conception, and other characteristics; models with interactions

\begin{tabular}{|c|c|c|c|c|c|c|}
\hline & \multicolumn{3}{|c|}{ Model 4} & \multicolumn{3}{|c|}{ Model 5} \\
\hline & $\mathrm{b}$ & SE & & $\mathrm{b}$ & SE & \\
\hline \multicolumn{7}{|l|}{ Age at birth (omitted=age 20-24) } \\
\hline Under 18 & -0.36 & 0.26 & & -0.41 & 0.26 & \\
\hline $18-19$ & -0.12 & 0.19 & & -0.17 & 0.20 & \\
\hline $25-29$ & 0.39 & 0.12 & ** & 0.39 & 0.12 & ** \\
\hline 30 and over & 0.80 & 0.13 & $* \star *$ & 0.79 & 0.13 & *** \\
\hline \multicolumn{7}{|c|}{ Relationship status at conception (omitted=married) } \\
\hline Never married, not cohabiting & -1.89 & 0.11 & $* * *$ & -2.44 & 0.15 & *** \\
\hline Never married, cohabiting & -1.03 & 0.08 & $* \star *$ & -1.30 & 0.11 & *** \\
\hline Previously married, not cohabiting & -1.78 & 0.25 & $* * *$ & -2.11 & 0.32 & *** \\
\hline Previously married, cohabiting & -0.65 & 0.13 & $* \star \star$ & -0.79 & 0.16 & *** \\
\hline \multicolumn{7}{|l|}{ Parity (omitted=second birth) } \\
\hline First birth & 0.29 & 0.11 & * & 0.32 & 0.11 & ** \\
\hline Third or higher order birth & 0.12 & 0.15 & & 0.11 & 0.15 & \\
\hline Year & -0.03 & 0.01 & ** & -0.02 & 0.01 & ** \\
\hline \multicolumn{7}{|l|}{ Race (omitted=non-Hispanic white) } \\
\hline Native-born Hispanic & 0.08 & 0.10 & & 0.15 & 0.11 & \\
\hline Foreign-born Hispanic & 0.36 & 0.12 & ** & 0.01 & 0.14 & \\
\hline Non-Hispanic black & -0.28 & 0.09 & ** & -0.83 & 0.14 & *** \\
\hline \multicolumn{7}{|c|}{ Family status at age 14 (omitted=not living with both biological parents) } \\
\hline Living with both biological parents & 0.12 & 0.07 & & 0.12 & 0.07 & \\
\hline \multicolumn{7}{|c|}{ Respondent's mother's education (omitted=high school degree/GED) } \\
\hline Missing & 0.11 & 0.23 & & 0.09 & 0.23 & \\
\hline Less than HS & 0.03 & 0.09 & & 0.05 & 0.09 & \\
\hline Any college & -0.08 & 0.08 & & -0.08 & 0.08 & \\
\hline
\end{tabular}


Table 3: $\quad$ (Continued)

\begin{tabular}{|c|c|c|c|c|c|c|}
\hline & \multicolumn{3}{|c|}{ Model 4} & \multicolumn{3}{|c|}{ Model 5} \\
\hline & $\mathrm{b}$ & SE & & $\mathrm{b}$ & SE & \\
\hline \multicolumn{7}{|c|}{ Respondent's mother's age at first birth (omitted=20-24) } \\
\hline Missing & 0.21 & 0.25 & & 0.22 & 0.25 & \\
\hline Under 18 & -0.08 & 0.10 & & -0.08 & 0.10 & \\
\hline $18-19$ & 0.07 & 0.08 & & 0.08 & 0.08 & \\
\hline Age 25 and over & -0.05 & 0.10 & & -0.03 & 0.10 & \\
\hline \multicolumn{7}{|c|}{ Education at time of conception (omitted=no high school degree) } \\
\hline High school degree & 0.11 & 0.08 & & 0.09 & 0.08 & \\
\hline \multicolumn{7}{|l|}{ Interactions: Parity $\mathrm{x}$ age } \\
\hline First birth $\mathrm{x}$ under age 20 & -0.09 & 0.22 & & -0.04 & 0.22 & \\
\hline First birth $\times 25-29$ & 0.29 & 0.16 & & 0.25 & 0.16 & \\
\hline First birth $\times 30$ and over & -0.02 & 0.16 & & -0.07 & 0.17 & \\
\hline Third+ birth $x$ age $25-29$ & -0.61 & 0.20 & ** & -0.59 & 0.20 & ** \\
\hline Third + birth $x$ age 30 and over & -0.78 & 0.19 & $\star \star \star *$ & -0.75 & 0.19 & *** \\
\hline \multicolumn{7}{|c|}{ Interactions: Foreign-born Hispanic $\mathrm{x}$ relationship status } \\
\hline Never married, not cohabiting & & & & 0.59 & 0.36 & \\
\hline Never married, cohabiting & & & & 0.82 & 0.20 & *** \\
\hline Previously married, not cohabiting & & & & 1.38 & 0.66 & * \\
\hline Previously married, cohabiting & & & & 0.48 & 0.43 & \\
\hline \multicolumn{7}{|c|}{ Interactions: African-American x relationship status } \\
\hline Never married, not cohabiting & & & & 1.43 & 0.22 & *** \\
\hline Never married, cohabiting & & & & 0.74 & 0.20 & *** \\
\hline Previously married, not cohabiting & & & & 0.58 & 0.72 & \\
\hline Previously married, cohabiting & & & & 0.67 & 0.34 & \\
\hline Intercept & 50.47 & 16.69 & ** & 48.51 & 16.80 & ** \\
\hline Pseudo-log likelihood & & 11.3 & & & 78.7 & \\
\hline
\end{tabular}

Data: National Survey of Family Growth, 2002. N = 6398 births to 3646 women; standard errors corrected for clustering. See text for details of variables and sample. $p \leq .05 ;{ }^{* \star} p \leq .01 ;{ }^{* \star *} p \leq .001$ 
Model fit improves between Model 3 (Table 2) and Model 4, indicating that there is statistically significant variation by parity in the association between age and planning status and statistically significant variation by age in the parity-planning status relationship. In Model 4, the main effects of age for women under age 18 and age 18-19 are not statistically different from zero. These coefficients represent the association between age and planning status for second and third births (the omitted category for this age group) and indicate that, for births after the first birth, there is little variation in planning status among births to women in their teens and in their early twenties. These associations are shown in Figure 1, depicting predicted probabilities for age differences in planning status for first, second, and third and higher-order births. The age differences are largest for first births and are small for third and higher-order births. That is, age differences in planning status are driven by differences at low parities; among high parity births, age is not strongly related to planning status. Women who have higher order births in their late twenties or thirties of necessity started childbearing before those ages. It may be that the age at which women start childbearing is more strongly related to the planning status of births than the timing of a particular birth. The significant age-parity interactions, taken together with the reduced relationship between age and planning status for high-parity births, suggest that the relationship between age and planning status is not primarily due to chronological effects of age but rather is related to the social processes associated with the postponement of first births among some groups of women.

To test the hypothesis that the likelihood of planned childbearing outside of marriage varies by race-ethnicity (Hypothesis 2a), Model 5 includes interactions between race-ethnicity and relationship status at conception. Exploratory analysis found that interaction terms for U.S.-born Hispanic women were neither individually nor jointly significant and did not add to model fit, so these terms are not included in the models presented here. Results for births to previously married women varied depending on whether births with imputed relationship status were included in analysis; variations are discussed in more detail in the appendix. Results for previously married women should therefore be interpreted with caution. In particular, the interaction coefficients for births to previously married women not cohabiting were highly sensitive to the imputation of relationship status for births with missing data (see appendix for details). We conclude that these terms are not reliable estimates and do not discuss them. 
Figure 1: Predicted probability that a birth will be planned, by age and parity

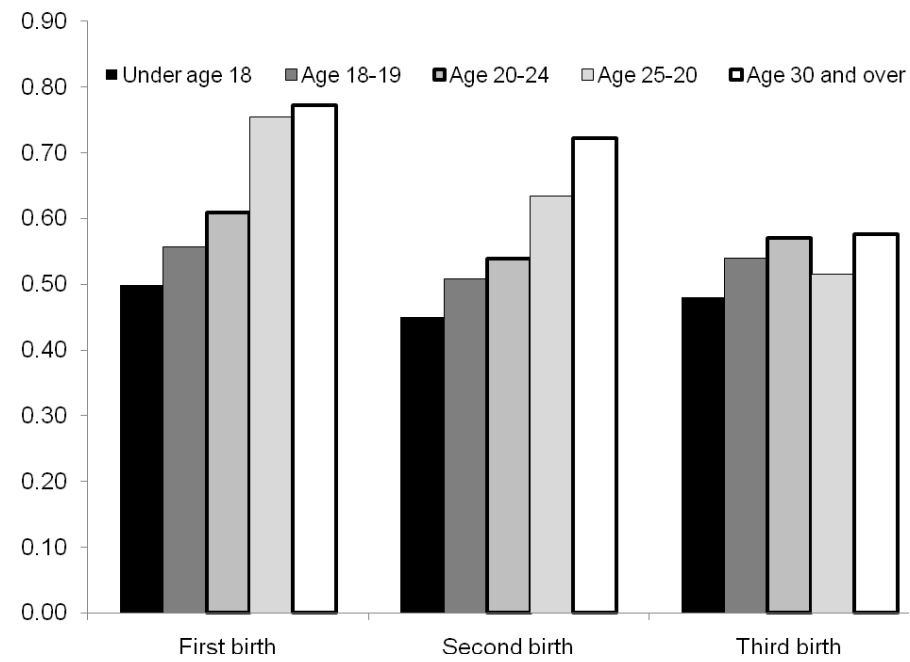

Data: National Survey of Family Growth, 2002. Predictions based on model 4, Table 3. Predicted probabilities generated based on births in 1996 to married non-Hispanic white women who grew up in intact families, who had a high school degree at the time of conception, and whose mothers had a high school degree and had a first birth at age 20-24.

Statistically significant interaction terms indicate that the association between planning status of births and relationship status at conception does vary by raceethnicity among non-Hispanic white women, foreign-born Hispanic women, and African American women. The main terms for the relationship status variables are negative in this model, as in Model 4, and on the whole slightly larger in magnitude than in Model 4. These terms represent the association between relationship status and planning status for non-Hispanic white women and native-born Hispanic women, the omitted categories. Predicted probabilities generated from Model 5 are shown in Figure 2.

The general pattern of differences by relationship status is the same across all raceethnic groups: the odds that a birth is planned are largest for married women and smallest for never-married lone mothers for women in each group. However, the magnitude of these differences varies. For foreign-born Hispanic women, the proportion of births to cohabiting women that are planned is larger than for other race-ethnic groups. That is, the negative association between cohabitation (relative to marriage) and planning status is weaker for foreign-born Hispanic women than for non-Hispanic white women. These results are consistent with previous research suggesting that cohabiting 
relationships are more likely to be long-term, stable relationships among Hispanic women than among white women. Differences by relationship status in the planning status of births are smaller for African American women than for women of other raceethnic groups: relative to births conceived within a marriage, births to single and cohabiting women are less likely to be planned, but this difference between union statuses is smaller than in other race-ethnic groups.

Figure 2: Predicted probability that a birth will be planned, by relationship status and race-ethnicity

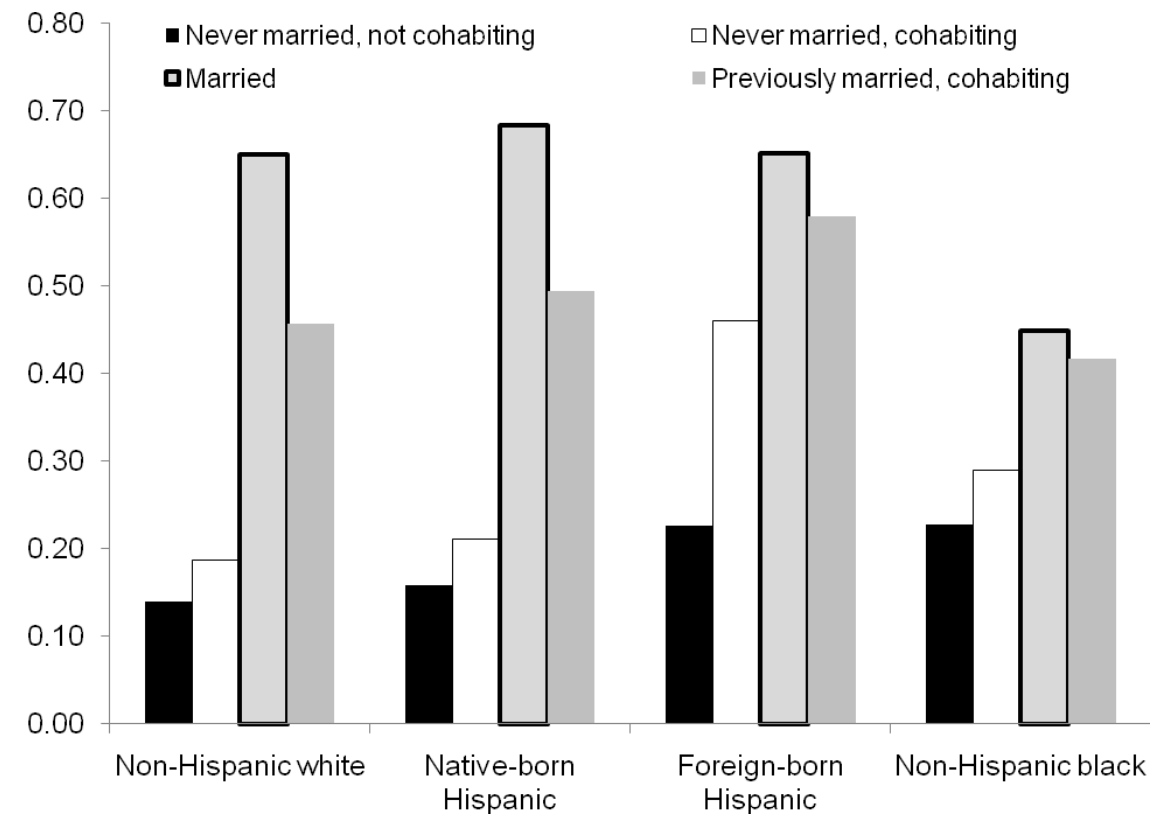

Data: National Survey of Family Growth, 2002. Predictions based on model 5, Table 3. Predicted probabilities generated based on second births in 1996 to women age 25-29 who grew up in intact families, who had a high school degree at the time of conception, and whose mothers had a high school degree and had a first birth at age 20-24. Predictions for previously married women who are not cohabiting are not included due to data problems (see Appendix). 


\section{Discussion}

It is often assumed that unplanned fertility occurs primarily among young and unmarried women, and in the past, this assumption was largely true. However, given the dramatic changes in the demographic characteristics of American mothers as fertility shifts to older ages and increasingly occurs outside of marriage, it is no longer clear whether this assumption holds. Our analysis first assessed whether the traditional age-dependence of fertility planning still exists, and secondarily examined how parity, relationship status, and race-ethnicity are jointly associated with planning status.

We found that age is strongly associated with the planning status of births in the United States. But this analysis shows that the association is highly contingent: it is reduced in magnitude when relationship status is controlled (and to a lesser extent when other variables are taken into account) and is stronger for first and second births than for higher-parity births. These results suggest that the higher proportion of planned births among women in their late twenties and early thirties is not primarily due to causal processes related to aging, such as increased knowledge or motivation to employ contraception. Instead, variation by age in the proportion of planned births appears to reflect social norms regarding the appropriate context for childbearing, and these norms vary by parity and relationship context.

Births in the United States are increasingly taking place in cohabiting unions and outside of coresidential relationships. Despite this variation in fertility behavior, there continue to be strong preferences for births within marriage, as reflected by the strong positive association between marriage and planned births. Although births conceived by women in cohabiting relationships are more likely to be planned than births outside of coresidential relationships, cohabitation has not yet joined marriage as a preferred context for having children. Among African American women, for whom the rates of nonmarital childbearing are highest, the association between union status and planning status of births is weaker than among non-Hispanic white women. As cohabiting and non-union birth rates continue to increase among other racial and ethnic groups in our society, these associations may continue to decline among other race-ethnic groups as well.

Despite strong bivariate associations between planning status of births and mother's socioeconomic status as measured by education and family background, socioeconomic characteristics do not predict planning status of births in a multivariate context. Controlling for the timing and relationship context of births appears to fully explain the higher proportion of unplanned births among economically disadvantaged women. During the 1990s, childbearing behavior became increasingly stratified in the United States, with early nonmarital childbearing in the teens and early twenties increasingly concentrated among economically disadvantaged women (Ellwood and 
Jencks 2004; McLanahan 2004; Martin 2004; Sullivan 2005). These results suggest that planning status of births is part of this cluster of fertility behavior.

\subsection{Limitations}

As with nearly all studies on birth wantedness and planning status, we are limited to retrospective measures, which are known to misrepresent behavior when compared to prospective measures of fertility plans and behaviors. The directions of bias in these measures are difficult to predict. Some women may feel that unplanned births are socially unacceptable and overstate their degree of planning. Other women may perceive stigma against the situation in which they had a child and report a pregnancy as unplanned as a way of reducing their responsibility for the decision. These misreports may result from either a conscious misrepresentation in the context of a survey interview or an internal process of reinterpretation of the circumstances of a pregnancy; to the extent that these misreports occur systematically among certain groups of women (e.g., specific racial or ethnic groups, cohabiting mothers, older or younger women), they may bias our results. In general, however, retrospective measures of fertility plans have been shown to be good predictors of key outcomes (Bachrach and Newcomer 1999; Joyce, Kaestner, and Korenman 2002).

A limitation which we share with other individual-level research on fertility is the inadequacy of survey reports of abortion. (We are also missing measures of many other proximate determinants of fertility, including sexual frequency and individual fecundability.) Our analysis captures only pregnancies that were carried to term, and our results are not generalizable to conceptions. Differential rates of abortion of unplanned pregnancies suggest that associations between race-ethnicity and planning status and relationship status and planning status would be stronger if we were able to study conceptions instead of births. For instance, married women are less likely to terminate an unplanned pregnancy than unmarried women, so unplanned birth rates understate the difference in conceptions by marital status (Finer and Henshaw 2006). Associations between age and planning status, on the other hand, might be weaker for conceptions than pregnancies, since older women have fewer unplanned conceptions but higher proportions of unplanned pregnancy ending in abortion (ibid.).That is, abortion appears to be one of the mechanisms driving age differences in unplanned births. This analysis should therefore be interpreted as an examination of the experiences of mothers and children rather than the mechanisms explaining unplanned fertility.

Another limitation of our work is the inability to situate childbearing within an educational or occupational history. Thus, we cannot definitively state whether having a 
planned or unplanned birth led to lower socioeconomic status or vice versa. Finally, we find no difference in the relationship between union status and birth planning for U.S.-born Hispanics, contrary to previous research that has suggested greater acceptance of cohabiting births among Hispanics than among non-Hispanic whites (Loomis and Landale 2004; Manning 2001; Manning and Landale 1996; Musick 2002; Musick 2007). This variation in results may stem from the relatively small samples of Hispanic women in the $2002 \mathrm{NSFG}$, an inability to differentiate among different national origin groups, or differences in sampling procedures and samples used in earlier research. We do find interactions with relationship status for foreign-born Hispanics as predicted by prior research.

\subsection{Conclusion}

The demographic changes among mothers that have occurred over the past few decades in the United States (and in most developed countries) are unlikely to reverse, and the two trends (rising age of mothers and increasing proportion of nonmarital births) may counteract each other in terms of their impact on overall rates of planned and unplanned births. The average age at first birth is likely to continue to rise, although this may obscure a bifurcation of fertility into a group of early childbearers and later childbearers (Sullivan 2005). Still, if more births occur among women who delayed childbearing to later ages, it is reasonable to expect that the United States might again experience a modest decline in unplanned fertility. The extent of this decline, however, is contingent on the evolving relationship between cohabitation and childbearing. As cohabitation becomes an increasingly acceptable locus for childbearing and childrearing, the weaker association between cohabitation and planned fertility (relative to marriage) may attenuate or disappear, and cohabitation and marriage may become equivalent as a family form, as is the case in some European countries (Kiernan 2002). To the extent that cohabitation, and nonmarital unions overall, remain a less preferred locus for childbearing, there will likely be little decline in unplanned fertility, and there may even be an uptick as more births occur outside of marriage. 


\section{References}

Bachrach, C. and Newcomer, S. (1999). Intended Pregnancies and Unintended Pregnancies: Distinct Categories or Opposite Ends of a Continuum? Family Planning Perspectives 31(5): 251-252. doi:10.2307/2991577.

Boonstra, H.D., Gold, R.B., Richards, C.L., and Finer, L.B. (2006). Abortion in Women's Lives. New York: Guttmacher Institute.

Bradburn, E.M., Berger, R., Xiaojile, L., Katharin, P., and Rooney, K. (2003). A Descriptive Summary of 1999-2000 Bachelor's Degree Recipients 1 Year Later: With an Analysis of Time to Degree. Washington, D.C.: National Center for Education Statistics. Statistical Analysis Report NCES-2003-165.

Bumpass, L.L. and Lu, H.-H. (2000). Trends in Cohabitation and Implications for Chidlren's Family Contexts in the United States. Population Studies 54(1): 2941. doi:10.1080/713779060.

Centers for Disease Control and Prevention [CDC] (2010). National Center for Health Statistics. VitalStats. http://www.cdc.gov/nchs/nvss.htm. Accessed June 14, 2010.

Chandra, A., Martinez, G.M., Mosher, W.D., Abma, J.C., and Jones, J. (2005). Fertility, Family Planning, and the Reproductive Health of U.S. Women: Data from the 2002 National Survey of Family Growth. Hyattsville, MD: National Center for Health Statistics. Vital Health Statistics 23(5).

Crissey, S.R. (2005). Effect of Pregnancy Intentions on Child Well-Being and Development: Combining Retrospective Reports of Attitude and Contraceptive Use. Population Research and Policy Review 24(6): 593-615. doi:10.1007/s11113-005-5734-1.

Edwards, M.E. (2002). Education and Occupations: Reexamining the Conventional Wisdom About Later First Births Among American Mothers. Sociological Forum 17: 423-443. doi:10.1023/A:1019679023616.

Ellwood, D.T. and Jencks, C. (2004). The Uneven Spread of Single Parent Families: What Do We Know? Where Do We Look for Answers? In: Neckerman, K.M. (ed.). Social Inequality. New York: Russell Sage Foundation: 3-77.

Finer, L.B. and Henshaw, S.K. (2006). Disparities in Rates of Unintended Pregnancy in the United States, 1994 and 2001. Perspectives on Sexual and Reproductive Health 38(2): 90-96. doi:10.1363/3809006. 
Guzman L., Manlove, J., and Moore, K. (2006). The Intendedness of Childbearing: Taking a Closer Look at Its Meaning. Population Association of America Annual Meetings, Los Angeles, CA.

Hagewen, K.J. and Morgan, S.P. (2005). Intended Parity and Ideal Family Size in the United States, 1970-2005. Population and Development Review 31(3): 507-527. doi:10.1111/j.1728-4457.2005.00081.x.

Henshaw, S.K. (1998). Unintended Pregnancy in the United States. Family Planning Perspectives 30(1): 24-46. doi:10.2307/2991522.

Heuveline, P. and Timberlake, J.M. (2004). The Role of Cohabitation in Family Formation: The United States in Comparative Perspective. Journal of Marriage and Family 66(5): 1214-1230. doi:10.1111/j.0022-2445.2004.00088.x.

Hummer, R.A., Hack, K.A., and Raley, R.K. (2004). Retrospective Reports of Pregnancy Wantedness and Child Well-Being in the United States. Journal of Family Issues 25(3): 404-428. doi:10.1177/0192513X03257712.

Jones, R.K. and Kost, K. (2007). Underreporting of Induced and Spontaneous Abortion in the United States: An Analysis of the 2002 National Survey of Family Growth. Studies in Family Planning 38(3): 187-197. doi:10.1111/j.17284465.2007.00130.x.

Joyce, T.J., Kaestner, R., and Korenman, S. (2002). Retrospective Assessments of Pregnancy Intention. Demography 39(1): 199-213. doi:10.1353/dem.2002.0006.

Kennedy, S. and Bumpass, L. (2008). Cohabitation and Children's Living Arrangements: New Estimates from the United States. Demographic Research 19(47): 1663-1692. doi:10.4054/DemRes.2008.19.47.

Kiernan, K. (2002). Cohabitation in Western Europe: Trends, Issues, and Implications. In: Booth, A. and Crouter, A.C. (eds.). Just Living Together: Implications of Cohabitation on Families, Children, and Social Policy. Mahwah, NJ: Erlbaum: 3-31.

Korenman, S., Kaestner, R., and Joyce, T.J. (2001). Unintended Pregnancy and the Consequences of Nonmarital Childbearing. In: Wu, L.L. and Wolfe, B. (eds.). Out of Wedlock: Causes and Consequences of Nonmarital Fertility. New York: Russell Sage Foundation: 259-286.

Koropeckyj-Cox, T., Pienta, A.M., and Brown, T.H. (2007). Women of the 1950s and the "Normative" Life Course: The Implications of Childlessness, Fertility, and Marital Status for Psychological Well-Being in Late Midlife. International 
Journal of Aging and Human Development 64: 299-330. doi:10.2190/8PTLP745-58U1-3330.

Landale, N.S. and Fennelly, K. (1992). Informal Unions Among Mainland Puerto Ricans: Cohabitation or an Alternative to Legal Marriage. Journal of Marriage and the Family 54: 269-280. doi:10.2307/353058.

Landale, N.S. and Oropesa, R.S. (2007). Hispanic Families: Stability and Change. Annual Review of Sociology 33: 381-405. doi:10.1146/annurev.soc.33.040406.131655.

Loomis, L.S. and Landale, N.S. (1994). Nonmarital Cohabitation and Childbearing among Black and White American Women. Journal of Marriage and Family 56(4): 949-962. doi:10.2307/353605.

Manning, W.D. and Landale, N.S. (1996). Racial and Ethnic Differences in the Role of Cohabitation in Premarital Childbearing. Journal of Marriage and the Family 58: 63-77. doi:10.2307/353377.

Manning, W.D. (2001). Childbearing in Cohabiting Unions: Racial and Ethnic Differences. Family Planning Perspectives 33(5): 217-223. doi: $10.2307 / 2673785$.

Martin, J.A., Hamilton, B.E., Sutton, P.D., Ventura, S.J., Menacker, F., Kirmeyer, S., and Mathews, T.J. (2009). Births: Final Data for 2006. National Vital Statistics Reports: 57(7). Hyattsville, MD: National Center for Health Statistics.

Martin, S.P. (2004). Delayed Marriage and Childbearing: Implications and Measurement of Diverging Trends in Family Timing. In: Neckerman, K.M. (ed.). Social Inequality. New York: Russell Sage Foundation: 79-118.

Martinez, G.M., Chandra, A., Abma, J.C., Jones, J., and Mosher, W.D. (2006). Fertility, Contraception, and Fatherhood: Data on Men and Women from Cycle 6 (2002) of the National Survey of Family Growth. Vital Health Statistics 23 (26). Hyattsville, MD: National Center for Health Statistics.

Matthews, T.J. and Hamilton, B.E. (2009). Delayed Childbearing: More Women are Having Their First Child Later in Life. NCHS Data Brief No. 29. Hyattsville, MD: National Center for Health Statistics.

McLanahan, S. (2004). Diverging Destinies: How Children Are Faring Under the Second Demographic Transition. Demography 41(4): 607-627. doi:10.1353/dem.2004.0033. 
Miller, W.B. (1986). Proception: An Important Fertility Behavior. Demography 23(4): 579-594. doi:10.2307/2061352.

Mincieli, L., Manlove, J., McGarrett, M., Moore, K., and Ryan, S. (2007). The Relationship Context of Births Outside of Marriage: The Rise of Cohabitation. Child Trends Research Brief 2007-13. Washington, DC: Child Trends.

Mirowsky, J. and Ross, C.E. (2002). Depression, Parenthood, and Age at First Birth. Social Science and Medicine 54: 1281-1298. doi:10.1016/S02779536(01)00096-X.

Morgan, S.P. (1996). Characteristic Features of Modern American Fertility: A Description of Late Twentieth-Century US Fertility Trends and Differentials. Population and Development Review 22(Supplement: Fertility in the United States: New Patterns, New Theories): 1-45.

Morgan, S.P. (2003). Is Low Fertility a Twenty-First-Century Demographic Crisis? Demography 40(4): 589-603. doi:10.1353/dem.2003.0037.

Morgan, S.P. and Rindfuss, R.R. (1999). Reexamining the Link of Early Chidlbearing to Marriage and to Subsequent Fertility. Demography 36(1): 56-75. doi:10.2307/2648134.

Musick, K. (2002). Planned and Unplanned Childbearing among Unmarried Women. Journal of Marriage and the Family 64(4): 915-929. doi:10.1111/j.17413737.2002.00915.x.

Musick, K. (2007). Cohabitation, Nonmarital Childbearing, and the Marriage Process. Demographic Research 16(9): 249-286. doi:10.4054/DemRes.2007.16.9.

Oropesa, R.S. (1996). Normative Beliefs about Marriage and Cohabitation: A Comparison of Non-Latino Whites, Mexican Americans, and Puerto Ricans. Journal of Marriage and the Family 58: 49-62. doi:10.2307/353376.

Raley, R.K. (2001). Increasing Fertility in Cohabiting Unions: Evidence for the Second Demographic Transition in the United States? Demography 38(1): 59-66. doi:10.1353/dem.2001.0008.

Rindfuss, R.R., Morgan, S.P., and Offutt, K. (1996). Education and the Changing Age Pattern of American Fertility: 1963-1989. Demography 33(3): 277-290. doi:10.2307/2061761.

Rindfuss, R.R., Morgan, S.P., and Swicegood, C.G. (1988). First Births in America: Changes in the Timing of Parenthood. Berkeley: University of California Press. 
Rossier, C. (2003). Estimating Induced Abortion Rates: A Review. Studies in Family Planning 34(2): 87-102. doi:10.1111/j.1728-4465.2003.00087.x.

Schoen, R., Kim, Y.J., Nathanson, C.A., Fields, J., and Astone, N.M. (1997). Why Do Americans Want Children? Population and Development Review 23(2): 333358. doi:10.2307/2137548.

Sullivan, R. (2005). The Age Pattern of First-Birth Rates Among U.S. Women: The Bimodal 1990s. Demography 42(2): 259-273. doi:10.1353/dem.2005.0018.

Thomson, E. and Brandreth, Y. (1995). Measuring Fertility Demand. Demography 32(1): 81-96. doi:10.2307/2061898.

Thornton, A. and Young-DeMarco, L. (2001). Four Decades of Trends in Attitudes Toward Family Issues in the United States: The 1960s Through the 1990s. Journal of Marriage and the Family 63(4): 1009-1037. doi:10.1111/j.17413737.2001.01009.x.

Trussell, J., Vaughan, B., and Stanford, J. (1999). Are All Contraceptive Failures Unintended Pregnancies? Evidence From the 1995 National Survey of Family Growth. Family Planning Perspectives 31(5): 246-247+260.

UNICEF (2001). A League Table of Teenage Births in Rich Nations. UNICEF Innocenti Research Center, Florence, Italy. Innocenti Report Card No 3.

U. S. Department of Health and Human Services (2000). Family Planning. Chapter 9 in Healthy People 2010. Washington, DC: U.S. Government Printing Office.

Ventura, S.J. (2009). Changing Patterns of Nonmarital Childbearing in the United States. NCHS Data Brief No. 18. Hyattsville, MD: National Center for Health Statistics.

Ventura, S.J. and Bachrach, C.A. (2000). Nonmarital Childbearing in the United States, 1940-1999. National Vital Statistics Reports Vol. 48, No. 16. Hyattsville, MD: National Center for Health Statistics.

Weller, R.H., Eberstein, I.W., and Bailey, M. (1987). Pregnancy Wantedness and Maternal Behavior During Pregnancy. Demography 24: 407-412. doi:10.2307/2061306.

Westoff, C.F. and Ryder, N.B. (1977). The Predictive Validity of Reproductive Intentions. Demography 14(4): 431-453. doi:10.2307/2060589.

Williams, L. and Abma, J.C. (2000). Birth Wantedness Reports: A Look Forward and a Look Back. Social Biology 47(3-4): 147-163. 
Wu, L.L. and Musick, K. (2008). Stability of Marital and Cohabiting Unions Following a First Birth. Population Research and Policy Review 27: 713-727. doi:10.1007/s11113-008-9093-6.

Wu, Z. and MacNeill, L. (2002). Education, Work, and Childbearing After Age 30. Journal of Comparative Family Studies 33: 191-213.

Zabin, L.S. (1999). Ambivalent Feelings About Parenthood May Lead to Inconsistent Contraceptive Use and Pregnancy. Family Planning Perspectives 31(5): 250251. doi:10.2307/2991576. 


\section{Appendix: Impact of imputed relationship status data on results}

As described in the data and methods section, problems with the skip patterns in the 2002 NSFG resulted in missing data on relationship status for some births. Table A-1 shows the final model (model 5) from Table 3 estimated using four different datasets representing four ways of treating these births. Column A includes the births with the relationship at conception as imputed by NCHS staff. Column B drops the imputed cases. Column C uses the imputed cases, but assigns all imputed relationship statuses to married. Column D uses the imputed cases and assigns all imputed relationship statuses to unmarried. (For this dataset, data on cohabitation were taken from the NSFG, since cohabitation questions were not affected by the problematic skip patterns.) Columns $\mathrm{C}$ and $\mathrm{D}$ demonstrate the range of possible error that could be introduced by the imputation. Column E shows the standardized range of the four estimates (calculated by subtracting the smallest coefficient of the four samples from the largest coefficient and dividing the difference by the smallest of the four standard errors).

The magnitude of the main terms for the relationship status variables differs across the four samples. This difference is approximately 1.2 standard errors for births to cohabiting women (both never married and previously married), about 0.8 standard errors for births to never married women not in a coresidential relationship, and about 0.5 standard errors for previously married women not in a coresidential relationship. These differences do not affect substantive conclusions.

The relationship status interactions also vary across the four samples. For nevermarried cohabiting women, this variation is negligible. For never-married women who are not cohabiting, the interaction terms for foreign-born Hispanic women vary in statistical significance, but the magnitude of the terms is similar across the four samples; the interaction terms for African-American women do not vary substantively. The variation across samples is largest for the interaction terms for previously married women, as expected since the imputed cases were largely births to previously married women. For cohabiting women, dates of cohabitation were collected even when marriage dates were not, making it possible to impute relationship context of births with some accuracy. For women not cohabiting, ascertaining relationship history is more difficult, and thus appears to have produced more "noise." Coefficients for births to previously married cohabiting women do not vary dramatically. Interaction terms are positive in all samples for foreign-born Hispanic women, but not always statistically significant. For African American women, the interactions are positive and statistically significant or very close to significant in all samples. For births to previously married women who are not cohabiting, the interaction terms for both African American and foreign born Hispanic women vary substantially across the four samples. The relatively smaller sample sizes for women of color make the interaction terms even more sensitive to the imputation of relationship context. Given this 
variation, we are reluctant to interpret the interaction terms for births to previously married women not cohabiting.

Table A-1: Logistic regression of planning status on age, relationship at conception, and other characteristics for four sets of data

\begin{tabular}{|c|c|c|c|c|c|c|c|c|c|c|}
\hline \multirow[b]{3}{*}{ Age at birth (omitted=20-24) } & \multicolumn{3}{|c|}{$\begin{array}{l}\text { A: Includes NSFG } \\
\text { imputed cases }\end{array}$} & \multicolumn{2}{|c|}{$\begin{array}{l}\text { B: Excludes NSFG } \\
\text { Imputed Cases }\end{array}$} & \multicolumn{2}{|c|}{$\begin{array}{c}\text { C: Imputed Cases } \\
\text { Assigned to Married }\end{array}$} & \multicolumn{2}{|c|}{$\begin{array}{c}\text { D: Imputed Cases } \\
\text { Assigned to Unmarried }\end{array}$} & \multirow[t]{2}{*}{$E$} \\
\hline & $b$ & \multicolumn{2}{|l|}{ SE } & $\mathrm{b}$ & SE & $\mathrm{b}$ & SE & $\mathrm{b}$ & SE & \\
\hline & & & & & & & & & & \\
\hline Under 18 & -0.41 & 0.26 & & -0.43 & 0.27 & -0.38 & 0.26 & -0.44 & 0.26 & 0.2 \\
\hline $18-19$ & -0.17 & 0.20 & & -0.14 & 0.20 & -0.15 & 0.20 & -0.18 & 0.19 & 0.2 \\
\hline $25-29$ & 0.39 & 0.12 & ** & 0.40 & $0.13^{* *}$ & 0.40 & $0.12^{* *}$ & 0.37 & 0.12 ** & 0.2 \\
\hline 30 and over & 0.79 & 0.13 & $\star \star \star *$ & 0.80 & $0.13^{* * *}$ & 0.78 & $0.13^{* * *}$ & 0.77 & $0.13^{* * *}$ & 0.2 \\
\hline \multicolumn{11}{|c|}{ Relationship status at conception (omitted=married) } \\
\hline Never married, not cohabiting & -2.44 & 0.15 & $* * *$ & -2.53 & $0.15^{* * *}$ & -2.41 & $0.15^{* * *}$ & -2.50 & $0.15^{* * *}$ & 0.8 \\
\hline Never married, cohabiting & -1.30 & 0.11 & $\star \star \star *$ & -1.38 & $0.11^{* * *}$ & -1.25 & $0.11^{* \star *}$ & -1.36 & $0.11 * * *$ & 1.2 \\
\hline $\begin{array}{l}\text { Previously married, not } \\
\text { cohabiting }\end{array}$ & -2.11 & 0.32 & $* * *$ & -2.11 & $0.36^{* * *}$ & -2.00 & $0.36^{* \star *}$ & -2.16 & $0.30^{* * *}$ & 0.5 \\
\hline Previously married, cohabiting & -0.79 & 0.16 & $\star \star \star *$ & -0.96 & $0.20^{* * *}$ & -0.86 & $0.20^{* \star *}$ & -0.83 & $0.14^{* * *}$ & 1.2 \\
\hline \multicolumn{11}{|l|}{ Parity (omitted=second birth) } \\
\hline First birth & 0.32 & 0.11 & ** & 0.33 & 0.12 ** & 0.33 & $0.11^{\star *}$ & 0.31 & 0.11 ** & 0.2 \\
\hline Third or higher order birth & 0.11 & 0.15 & & 0.18 & 0.16 & 0.10 & 0.15 & 0.13 & 0.15 & 0.5 \\
\hline Year & -0.02 & 0.01 & ** & -0.03 & 0.01 ** & -0.02 & $0.01 * *$ & -0.03 & 0.01 ** & 0.5 \\
\hline \multicolumn{11}{|c|}{ Race (omitted=non-Hispanic white) } \\
\hline Native-born Hispanic & 0.15 & 0.11 & & 0.19 & 0.12 & 0.13 & 0.11 & 0.18 & 0.11 & 0.5 \\
\hline Foreign-born Hispanic & 0.01 & 0.14 & & -0.07 & 0.15 & 0.02 & 0.14 & -0.05 & 0.15 & 0.7 \\
\hline Non-Hispanic black & -0.83 & 0.14 & $* \star *$ & -0.85 & $0.15^{* * *}$ & -0.83 & $0.13^{\star \star *}$ & -0.88 & $0.15^{* \star *}$ & 0.4 \\
\hline \multicolumn{11}{|c|}{ Family status at age 14 (omitted=living with both biological parents) } \\
\hline $\begin{array}{l}\text { Living with both biological } \\
\text { parents }\end{array}$ & 0.12 & 0.07 & & 0.11 & 0.08 & 0.14 & 0.07 & 0.11 & 0.07 & 0.4 \\
\hline \multicolumn{11}{|c|}{ Respondent's mother's education (omitted=high school degree) } \\
\hline Missing & 0.09 & 0.23 & & 0.04 & 0.25 & 0.08 & 0.24 & 0.08 & 0.24 & 0.2 \\
\hline Less than HS & 0.05 & 0.09 & & 0.03 & 0.10 & 0.04 & 0.09 & 0.05 & 0.09 & 0.2 \\
\hline Any college & -0.08 & 0.08 & & -0.09 & 0.08 & -0.08 & 0.08 & -0.07 & 0.08 & 0.1 \\
\hline
\end{tabular}


Hayford \& Guzzo: Age, relationship status, and the planning status of births

Table A-1: (Continued)

\begin{tabular}{|c|c|c|c|c|c|c|c|c|c|c|}
\hline & \multicolumn{2}{|c|}{$\begin{array}{l}\text { A: Includes NSFG } \\
\text { imputed cases }\end{array}$} & \multicolumn{2}{|c|}{$\begin{array}{l}\text { B: Excludes NSFG } \\
\text { Imputed Cases }\end{array}$} & \multicolumn{2}{|c|}{$\begin{array}{l}\text { C: Imputed Cases } \\
\text { Assigned to Married }\end{array}$} & \multicolumn{3}{|c|}{$\begin{array}{c}\text { D: Imputed Cases } \\
\text { Assigned to Unmarried }\end{array}$} & \multirow[t]{2}{*}{$\mathrm{E}$} \\
\hline & $\mathrm{b}$ & SE & b & SE & b & SE & $\mathrm{b}$ & SE & & \\
\hline \multicolumn{11}{|c|}{ Respondent's mother's age at first birth (omitted $=20-24$ ) } \\
\hline Missing & 0.22 & 0.25 & 0.26 & 0.26 & 0.25 & 0.25 & 0.23 & 0.25 & & 0.1 \\
\hline Under 18 & -0.08 & 0.10 & -0.02 & 0.10 & -0.08 & 0.10 & -0.07 & 0.10 & & 0.7 \\
\hline $18-19$ & 0.08 & 0.08 & 0.12 & 0.09 & 0.08 & 0.08 & 0.08 & 0.08 & & 0.5 \\
\hline Age 25 and over & -0.03 & 0.10 & -0.03 & 0.10 & -0.02 & 0.10 & -0.03 & 0.10 & & 0.1 \\
\hline \multicolumn{11}{|c|}{ Education at time of conception (omitted=no high school degree) } \\
\hline High school degree & 0.09 & 0.08 & 0.04 & 0.09 & 0.11 & 0.08 & 0.07 & 0.08 & & 0.8 \\
\hline \multicolumn{11}{|l|}{ Interactions: Parity $x$ age } \\
\hline First birth $\mathrm{x}$ under age 20 & -0.04 & 0.22 & -0.07 & 0.22 & -0.06 & 0.22 & -0.04 & 0.22 & & 0.2 \\
\hline First birth $\times 25-29$ & 0.25 & 0.16 & 0.26 & 0.17 & 0.25 & 0.16 & 0.27 & 0.16 & & 0.2 \\
\hline First birth $\times 30$ and over & -0.07 & 0.17 & -0.05 & 0.17 & -0.04 & 0.17 & -0.06 & 0.17 & & 0.2 \\
\hline Third+ birth $x$ age $25-29$ & -0.59 & $0.20^{* *}$ & -0.67 & 0.21 ** & -0.60 & 0.20 ** & -0.61 & 0.20 & ** & 0.4 \\
\hline Third+ birth $x$ age 30 and over & -0.75 & $0.19^{\star * \star}$ & -0.84 & $0.20^{* \star *}$ & -0.75 & $0.19^{* * *}$ & -0.77 & 0.19 & $* * *$ & 0.5 \\
\hline \multicolumn{11}{|c|}{ Interactions: Foreign-born Hispanic $\mathrm{x}$ relationship status } \\
\hline Never married, not cohabiting & 0.59 & 0.36 & 0.72 & 0.37 * & 0.64 & 0.36 & 0.66 & 0.36 & & 0.4 \\
\hline Never married, cohabiting & 0.82 & 0.20 *** & 0.90 & $0.21 * * *$ & 0.80 & 0.20 *** & 0.89 & 0.21 & $\star \star \star *$ & 0.5 \\
\hline $\begin{array}{l}\text { Previously married, not } \\
\text { cohabiting }\end{array}$ & 1.38 & 0.66 * & 0.28 & 1.08 & 0.18 & 1.09 & 1.64 & 0.62 & ** & 2.4 \\
\hline Previously married, cohabiting & 0.48 & 0.43 & 0.63 & 0.49 & 0.58 & 0.49 & 0.66 & 0.32 & * & 0.5 \\
\hline \multicolumn{11}{|c|}{ Interactions: African-American $\mathrm{x}$ relationship status } \\
\hline Never married, not cohabiting & 1.43 & $0.22 * \star *$ & 1.45 & $0.23^{* * *}$ & 1.43 & $0.22 * * *$ & 1.47 & 0.23 & $* * *$ & 0.2 \\
\hline Never married, cohabiting & 0.74 & $0.20^{* * *}$ & 0.75 & $0.21 * * *$ & 0.72 & $0.20^{* * *}$ & 0.78 & 0.21 & $* * *$ & 0.3 \\
\hline $\begin{array}{l}\text { Previously married, not } \\
\text { cohabiting }\end{array}$ & 0.58 & 0.72 & -0.29 & 1.06 & -0.31 & 1.06 & 1.13 & 0.54 & * & 2.7 \\
\hline Previously married, cohabiting & 0.67 & 0.34 & 0.91 & 0.45 * & 0.90 & 0.45 * & 0.80 & 0.29 & ** & 0.8 \\
\hline Intercept & 48.51 & $16.80^{* *}$ & 57.36 & $17.49^{* *}$ & 48.34 & 16.77 ** & 54.53 & 16.95 & $* *$ & 0.5 \\
\hline $\mathbf{N}$ & & 6398 & & 6009 & & 6398 & & 6398 & & \\
\hline
\end{tabular}

Data: National Survey of Family Growth, 2002. Standard errors corrected for clustering. See text for details of variables and sample. $p \leq .05 ;{ }^{* *} p \leq .01 ;{ }^{* * *} p \leq .001$. Columns identified in text. 